\title{
Determinant factors of toothache in 8- and 9-year-old schoolchildren, Belo Horizonte, MG, Brazil
}

\begin{abstract}
Eliane Paula Reis Barrêtto(a) Efigênia Ferreira e Ferreira ${ }^{(b)}$ Isabela Almeida Pordeus(c)
\end{abstract}

(a) MSc, Assistant Professor, School of Dentistry, Mário Penna Campus, Vale do Rio Verde University (UNINCOR), Belo Horizonte, MG, Brazil.

(b) $\mathrm{PhD}$, Associate Professor; (c) PhD, Head Professor - Dental School, Federal University of Minas Gerais (FO-UFMG), Belo Horizonte, MG, Brazil.

\section{Corresponding author:}

Eliane Paula Reis Barrêtto

Rua Hermilio Alves, 235 - apto. 201,

bloco I, Santa Tereza

Belo Horizonte - MG - Brazil

CEP: 31010-070

E-mail: barrettoeliane@gmail.com

\begin{abstract}
A cross-sectional study was carried out to determine the prevalence, severity and impact of toothache among schoolchildren associated with socio-demographic variables (gender, degree of maternal schooling, economic group, and oral health status). Six hundred and one 8- and 9-year-old children were randomly selected from schools in Belo Horizonte, MG, Brazil. After formal authorization was obtained from their parents, the children were interviewed and clinically examined by a single examiner. The Chi squared test was applied and the odds ratio obtained. The prevalence of toothache was $45.9 \%$ (276/601), of which $15.6 \%(94 / 601)$ had occurred during the previous month. Among the children who had experienced pain, 39.4\% (109/276) classified its severity as intense or very intense. Nearly $35 \%$ (96/276) were awoken by the pain, and $63.8 \%(176 / 276)$ were unable to carry out daily tasks as a result. The prevalence of pain was greater among children from less privileged economic groups, in which the mothers' level of schooling was lower (0-7 years of formal study) and who showed poorer conditions of oral health, determined by the presence of dental and periodontal pathology $(\mathrm{p} \leq 0.05)$. Gender did not influence either the experience of toothache or its severity and impact. The prevalence of toothache found in the age group between 8 and 9 years is very high and associated to social determinants and poorer conditions of oral health.
\end{abstract}

Descriptors: Child; Toothache; Socioeconomic factors. 


\section{Introduction}

The contemporary concept of health promotion suggests a global action with the objective of improving the quality of life, and quality of life involves the equilibrium and satisfaction of the individual in terms of self-esteem, pleasure and, principally, wellbeing. In this context, pain has great relevance as one of the most frequent symptoms of untreated oral disease, and because it may disrupt this equilibrium, with a negative impact on the quality of life. ${ }^{1}$

One of the greatest demands made on the dental profession is the reduction of pain and suffering. However, measures to evaluate toothache have not yet been included in the goals of health systems. ${ }^{2}$ The majority of the more consolidate dental pain studies have been undertaken with adults and the elderly. ${ }^{3-8}$ Therefore, epidemiological data on this pain in children and adolescents have only recently become a research object in Dentistry., ${ }^{1,9-13}$ The objective of this study was to evaluate the prevalence, severity and impact of toothache in children, as well as its relation to other variables such as the gender of the child, level of schooling of the mother, economic condition of the family, and oral health condition of the child.

\section{Material and Methods}

A cross-sectional study was undertaken in Belo Horizonte, MG, Brazil, which is divided into nine regional areas of local administration.

\section{Sampling}

The sample was made up of 601 schoolchildren aged eight and nine years, from schools chosen at random which offered primary school education, one from each of the nine regional areas. This was the chosen age group to comply with the method used by Shepherd et al. ${ }^{13}$ (1999) and because the adolescence has been beginning earlier, at approximately 10 years of age. The criteria of eligibility were: children present on the day of data collection, with authorization from the parents/guardians, and with good physical and psychological conditions at the time of the examination. The sample calculation was undertaken using an $\alpha$-value of 0.05 , a detectable error of $4 \%$ and the prevalence data of tooth- ache $(47.5 \%)$ from the study of Shepherd et al. ${ }^{13}$ (1999), on which the questionnaire used was based.

\section{Data collection}

The questionnaire, previously tested and adapted in two pilot studies, was applied in the form of an interview directly with the child, by a single researcher (the intra-examiner agreement was calculated on a tooth-by-tooth basis; the maximum and minimum Kappa values were 1.00 and 0.076, respectively; calibration was exercised for each clinical alteration). The data collected concerning toothache included prevalence, characteristics of the pain (location, cause, frequency and severity), impact on the child and his/her family, and action taken to alleviate the pain. Severity of pain included a measurement of intensity using a projective test consisting of a visual analogical scale ${ }^{9}$ with five infant faces (graduated scores from one to five representing very light to very intense pain), of both genders and black and white races.

Each child was also submitted to a standardized clinical examination (using gauze, cotton rolls and a mouth mirror), performed at school, under artificial light (Petzl headlamp). The child laid his/her head on a cushion on the lap of the examiner, and the examination was performed using standardized equipment for cross-infection control. Diagnostic criteria were adopted for the clinical examination taking into consideration the nature, location and type of oral alterations. Notation was by tooth, with the condition present or absent, regardless of its location. Simultaneously, the clinical condition of the deciduous and permanent teeth was recorded, in case two sources of pain were present. The code adopted, based on the criteria of the World Health Organization $^{14}$ (1997), was constructed from some of the possible causes of oral pain among children of the age group studied.

The dependant variables used were measured according to: 1. Prevalence - Presence of pain or recent pain (last month); 2. Severity - Manifestation of pain (crying and intensity of pain); 3. Impact on the child - Sleep disturbance and/or Unable to carry out daily activities. The independent variables were classified as: 1. Gender; 2. Level of schooling of the 
mother, in years of formal study (0-3 years, 4-7 years, $8-11$ years, $\geq 12$ years); 3 . Economic group $^{15}$ (classes A1/A2 - high group; classes B1/B2 - intermediate group; classes $\mathrm{C} / \mathrm{D} / \mathrm{E}$ - low group); and 4. oral alterations, divided into physiological processes (alterations in dentition - physiological mobility/tooth in the process of eruption) and pathological processes (alterations in teeth that included acute/chronic carious lesion involving dentin, involving pulp and isolated root; in the periodontium, such as spontaneous bleeding, changes in gingival morphology and tartar). Traumatism (fracture), inadequate restoration without caries and disturbance in dental formation with loss of substance ${ }^{14}$ were also observed and noted. The objective was to separate the toothache actually caused by present dental decay from other possible causes of pain.

Together with their free and informed consent, the parents/guardians provided information on their economic status, according to the Brazilian Economic Classification, ${ }^{15}$ in questionnaires distributed and collected by faculty or during meetings at school (rate of return: $88.1 \%$ ).

\section{Ethical and data analysis}

Appropriate treatment at health centers and emergency centers in the municipality was guaranteed to the children who presented oral health problems at clinical examination, with the support of the municipal health department. The study was approved by the Ethics Committee, Federal University of Minas Gerais, under report n. 180/01. The chi- squared test for association and comparison of proportions ( $\mathrm{p} \leq 0.05)$, and the odds ratio were used for data analysis, using the Statistical Package for Social Science, version 12.0 (SPSS Inc., Chicago, IL, USA).

\section{Results}

Fifty-five per cent of the children were females and $45 \%$ males. The prevalence of toothache was $45.9 \%(\mathrm{n}=276)$, and nearly $15.6 \%(\mathrm{n}=94)$ of the children had had dental pain in the previous 4-week period. Dental pain caused crying in 91/276 (33\%), and $109 / 276(39.4 \%)$ rated their pain as intense/very intense; 176/276 (63.8\%) were unable to carry out their daily activities because of the pain, and 96/276 $(34.8 \%)$ of the children woke up at night because of it.

Information concerning maternal schooling was obtained from 596 of the 601 interviewees. A statistically significant association was found between the level of schooling of the mother and economic group $\left(\chi^{2}=216.14 ;\right.$ d.f. $\left.=6 ; p=0.000\right)$. A significant association between maternal schooling/economic group and dental pain $\left(\chi^{2}=33.87\right.$, d.f $=3$, $\mathrm{p}=0.000)$, crying because of the pain $\left(\chi^{2}=21.10\right.$, d.f $=4, p=0.000$ ), intensity of the pain (Table 1 ) and waking up during the night $\left(\chi^{2}=15.23\right.$, d.f. $=3$, $\mathrm{p}=0.002)$ was identified.

The occurrence of pain tended to increase with the reduction in maternal schooling. Among children whose mothers had 0-3 years of formal schooling, the majority $(61.3 \%)$ reported toothache $(n=49 / 80)$, whereas the inverse was found among
Table 1 - Absolute and relative frequencies of the variable level of maternal schooling, in relation to degree of toothache intensity.

\begin{tabular}{|c|c|c|c|c|c|c|}
\hline \multirow[b]{2}{*}{$\begin{array}{c}\text { Schooling of } \\
\text { mother }\end{array}$} & \multicolumn{6}{|c|}{ Intensity of pain* } \\
\hline & $\begin{array}{c}\text { Very light pain / } \\
\text { light pain } \\
\mathrm{n}(\%)\end{array}$ & $\begin{array}{c}\text { Moderate } \\
\text { pain } \\
\mathrm{n}(\%)\end{array}$ & $\begin{array}{c}\text { Intense / very } \\
\text { intense pain } \\
n(\%)\end{array}$ & & $\begin{array}{l}\text { tal } \\
\%)\end{array}$ & $p$-value ${ }^{* * *}$ \\
\hline $0-3$ years & 19 (38.7) & $9(18.4)$ & 21 (42.9) & 49 & $(100.0)$ & 0.022 \\
\hline 4-7 years & $21(25.6)$ & $16(19.5)$ & $45(54.9)$ & 82 & (100.0) & 0.000 \\
\hline $8-11$ years & $23(46.0)$ & $11(22.0)$ & $16(32.0)$ & 50 & $(100.0)$ & 0.038 \\
\hline$\geq 12$ years & $53(57.0)$ & $15(16.1)$ & $25(26.9)$ & 93 & (100.0) & 0.000 \\
\hline Total & $116(42.4)$ & $51(18.6)$ & $107(39.0)$ & $274^{*}$ & $(100.0)$ & \\
\hline$p$-value** & 0.000 & 0.849 & 0.001 & & & \\
\hline
\end{tabular}

${ }^{*} \chi^{2}=20.70$, d.f. $=6, p=0.002 .{ }^{* *}$ Chi-squared test for comparison of proportions within each score. ${ }^{* * *}$ Chisquared test for comparison of proportions within each level of schooling. ${ }^{* * * *}$ Among the 276 children that felt pain, 274 reported the level of schooling of the mother. 
Table 2 - Absolute and relative frequencies of the clinical examination results, among children who had felt recent pain and those who did not feel toothache.

\begin{tabular}{|c|c|c|c|c|c|}
\hline \multirow{2}{*}{\multicolumn{2}{|c|}{$\begin{array}{l}\text { Results of the clinical } \\
\text { examination }\end{array}$}} & \multicolumn{4}{|c|}{ Experience of recent toothache } \\
\hline & & \multirow{2}{*}{$\begin{array}{c}\text { Yes }(n=94) \\
n(\%)\end{array}$} & \multirow{2}{*}{$\begin{array}{c}\text { No }(n=325) \\
n(\%) \\
238(73.2)\end{array}$} & \multirow{3}{*}{$\begin{array}{c}p \text {-value } \\
0.249\end{array}$} & \multirow{3}{*}{$\begin{array}{l}\text { Odds Ratio } \\
\text { (Cl 95\%) } \\
+\end{array}$} \\
\hline \multirow{2}{*}{$\begin{array}{l}\text { Alteration in } \\
\text { dentition }\end{array}$} & Yes & & & & \\
\hline & No & $19(20.2)$ & $87(26.8)$ & & \\
\hline \multirow{2}{*}{$\begin{array}{l}\text { Alteration in } \\
\text { teeth }\end{array}$} & Yes & $65(69.1)$ & $176(54.2)$ & \multirow{2}{*}{0.013} & \multirow{2}{*}{$\begin{array}{c}1.90 \\
(1.16-3.09)\end{array}$} \\
\hline & No & $29(30.9)$ & 149 (45.8) & & \\
\hline \multirow{2}{*}{$\begin{array}{l}\text { Alteration in } \\
\text { periodontium }\end{array}$} & Yes & $26(27.7)$ & $54(16.6)$ & \multirow{2}{*}{0.024} & \multirow{2}{*}{$\begin{array}{c}1.92 \\
(1.12-3.29)\end{array}$} \\
\hline & No & $68(72.3)$ & $271(83.4)$ & & \\
\hline
\end{tabular}

children whose mothers had 12 or more years of study, of which $66.5 \%(\mathrm{n}=185 / 278)$ had never felt toothache.

The data also show that of the 89 children who cried as a result of pain and responded about maternal schooling, $66.3 \% \quad(\mathrm{n}=59)$ were children of mothers from the two lowest levels of schooling (0-7 years). The opposite was observed among children who did not cry because of pain: $61.2 \%$ ( $\mathrm{n}=112 / 183)$ had mothers from the two highest levels of schooling ( $\geq 8$ years).

Ninety four children had their sleep interrupted (and responded about maternal schooling) and 60 (63.8\%) had mothers with the two lowest levels of schooling; or 179 children did not have their sleep interrupted, and 109 (60.9\%) had mothers with the highest levels of schooling. No association was observed between maternal schooling and inability to carry out daily activities because of the pain $\left(\chi^{2}=1.63\right.$, d.f $\left.=3, p=0.653\right)$, even when a separate analysis of each type of activity was performed.

Only the 94 children who had felt pain in the previous month were included in the analysis of the relationship between self reporting of pain and the state of oral health. Table 2 shows that the experience of recent toothache had a significant association only with alterations in teeth and in the periodontium. The children with these alterations showed, respectively, 1.90 and 1.92 times more chance of reporting recent toothache than those without them.

The result was different in relation to severity of pain. For children who cried because of pain, the majority showed alterations both in dentition and in teeth in equal proportions (i.e., physiological and pathological problems). In the analysis of the visu- al analogue scale of faces, the occurrence in equal proportions of alterations in dentition and in teeth was repeated with the scores of intermediate (score 3) and high intensity pain (intense to very intense pain/scores 4-5). Only scores 1-2 (very light to light pain) were statistically associated only to alterations in dentition or only to physiological problems. Both physiological and pathological alterations influenced the questions related to the impact of pain for the child, with no statistically significant relationship.

No statistically significant association was found between "visits to the dentist" and toothache prevalence. However, the motivating factor for dental consultation for the majority who reported toothache was the presence of "problems" $(55.1 \%)$, while for those who did not experience pain, the principal motive was "check-up and prevention" (61.3\%), where the association was clear $(\mathrm{p}=0.000)$.

Another relevant result was observed when comparing the report of toothache and the search for relief of this pain. The majority of children who were taken to the dentist to resolve their pain had mothers with the highest levels of schooling/economic group, while among the children whose mothers had lower levels of schooling/economic group, the most common measures to alleviate the pain were self medication or "no care" $\left(\chi^{2}=216.12\right.$; d.f. $\left.=5 ; \mathrm{p}=0.000\right)$.

\section{Discussion}

A strong association between level of maternal schooling and socioeconomic group is well established in the literature, ${ }^{16}$ and has been confirmed by the present study. The level of maternal schooling was used as the guidance variable in the analysis of association, giving more precise and comparable re- 
sults than the economic group, which has different ways of being measured. The mother has also been shown to be the principal provider when dealing with oral health care in infancy, ${ }^{17,18}$ influencing their children's behavior.

Low level of maternal schooling/economic group presented an association with an increased experience and severity of toothache. A similar relationship with severity has been shown in other studies with adults ${ }^{5,7,8}$ and children. , $^{1,911,13}$ Less privileged persons are more affected by disease and have less access to dental health care. ${ }^{8}$ The influence of the social component on the access to health services reflects the negative effects of socio-economic conditions which limits healthy choices and habits and adversely affects oral health. ${ }^{1,19,20}$ Children with a poor state of oral health in this study had 1.90 and 1.92 times more chance of having toothache than those without any pathology.

The majority of the children who were woken up at night because of pain were in less privileged economic situations, but its impact on their lives, measured as the ability to perform daily activities, was the same irrespective of economic status. Other studies show a more significant influence of social determinants on the impact of pain among children and adolescents. ${ }^{1,10}$

With a view to reduce the effects of bias in memory, only the 94 children who had felt pain in the previous month were included in the analysis of the relationship between self reporting of pain and the state of oral health. This restriction also reduced the influence of changes due to the progression of the disease or any dental treatment intervention.

The present study points to evidence that both pathological alterations and physiological alterations contribute to the severity ${ }^{9}$ and impact of pain. And when the pathology adds to the physiological problems, then the intensity of the pain increases. ${ }^{9}$ Cushing et al. ${ }^{4}$ (1986) showed that the traditional index DMF-t is not correlated to impacts experienced as pain, with the exception of problems related to eating. Periodontal indices as well did not have significant correlations with the impacts. Adulyanon et al. ${ }^{3}$ (1996) concluded that, even among people with a low experience of caries, the impact of oral alterations is as high as in populations with elevated indices of the disease.

In infant populations, some studies showed that even children without experience of caries had experienced toothache, which pointed to other non-carious causes of pain. ${ }^{1,13}$ To explain a higher frequency of reports of pain during a longitudinal study ${ }^{10}$ (20 years), some hypotheses were put forward: the polarization of the disease in certain less favored social groups, for which there was an increase in the disease, and the fact that the pain may have originated for reasons other than caries, e.g., eruption of teeth, problems in the temporomandibular articulation, stress because of poor financial conditions, and increase in the rate of orthodontic treatment.

The present study had limitations, mainly the lack of a multiple logistic regression analysis, because there was no adjustment of the variables to the model. However, the limitations were minimized because the stratification of the economic groups found in the sample was very similar to that of official statistics, ${ }^{15}$ demonstrating the representative character of the study. Moreover, a high intra-examiner agreement and response rate reinforced the internal validity of the study, and the methodology used was partially capable of quantifying the types of dental pain.

This study showed that children aged eight and nine years, in Belo Horizonte, have a high prevalence of toothache, representing a significant public health problem for the city. Furthermore, a great influence of social determinants in questions related to oral health and symptoms was shown. The experience of toothache was associated with some pathological causes, principally dental and periodontal ones, or in other words, with a poor clinical oral condition. Children with these alterations presented a higher chance of having toothache than those without them. In addition, their pain is exacerbated since they remain without adequate care due to poor economic conditions. ${ }^{8}$ Simple preventive care would reduce the costs involved in providing emergency services and secondary care, such as restoration. ${ }^{7}$ The majority of the children without experience of toothache reported going to the dentist for checkups and prevention. 
It was observed, however, that even the presence of toothache is not sufficient to break the access barriers faced by people of low income. Removing the infirmity causing the pain must become an explicit goal of any dental health care system which measures outcomes of oral health. ${ }^{1,21}$

There is a need to consider what is really responsible for the creation and maintenance of good health which includes education, safe conditions of work and housing, as well as social assistance. The inadequate form of care that people receive within public health institutions, which is especially true in Brazil, creates an access barrier to professional help. A change in the focus of interventions towards the determinant factors of disease, through a series of complementary actions, is necessary, as are a more active participation of the community in local health questions and multidisciplinary work in cooperation

\section{References}

1. Slade GD. Epidemiology of dental pain and dental caries among children and adolescents. Community Dent Health. 2001;18(4):219-27.

2. Naidoo S, Chikte UME, Sheiham A. Prevalence and impact of dental pain in 8-10-year-olds in the Western Cape. SADJ. 2001;56(11):521-3.

3. Adulyanon S, Vourapukjaru J, Sheiham A. Oral impacts affecting daily performance in a low dental disease Thai population. Community Dent Oral Epidemiol. 1996;24(6):385-9.

4. Cushing AM, Sheiham A, Maizels J. Developing socio-dental indicators: the social impact of dental disease. Community Dent Health. 1986;3(1):3-17.

5. Locker D, Jokovic A. Three-year changes in self-perceived oral health status in an older Canadian population. J Dent Res. 1997;76(6):1292-7.

6. Petersen PE. Social inequalities in dental health: towards a theoretical explanation. Community Dent Oral Epidemiol. 1990;18(3):153-8.

7. Reisine ST. Dental disease and work loss. J Dent Res. 1984;63(9):1158-61.

8. Vargas CM, Macek MD, Marcus SE. Sociodemographic correlates of tooth pain among adults: United States, 1989. Pain. 2000;85(1-2):87-92.

9. Barrêtto EPR, Ferreira EF, Pordeus IA. Evaluation of toothache severity in children using a visual analogical scale of faces. Pediatr Dent. 2004;26(6):485-91.

10. Honkala E, Honkala S, Rimpela A, Rimpela M. The trend and risk factors of perceived toothache among Finnish adolescents from 1977 to 1997. J Dent Res. 2001; 80(9):1823-7. with the society (social control). Policies which promote health and wellbeing, with social support, may have an effect in reducing the gap between the rich and the poor, and could have profound implications for public health. ${ }^{19}$

\section{Conclusion}

This study showed that a great group of children aged eight and nine years, in Belo Horizonte, MG, Brazil, has a high prevalence and impact of toothache, associated to social determinants and poorer conditions of oral health, suggesting the presence of a significant public health problem in the city.

\section{Acknowledgments}

This study had the financial support of the $\mathrm{Na}$ tional Council for Scientific and Technological Development (CNPq).

11. Nomura LH, Bastos JLD, Peres MA. Dental pain prevalence and association with dental caries and socioeconomic status in schoolchildren, Southern Brazil, 2002. Braz Oral Res. 2004;18(2):134-40.

12. Ratnayake N, Ekanayake L. Prevalence and impact of oral pain in 8-year-old children in Sri Lanka. Int J Paediatric Dent. 2005;15(2):105-12.

13. Shepherd MA, Nadanovsky P, Sheiham A. The prevalence and impact of dental pain in 8-year-old school children in Harrow, England. Br Dent J. 1999;187(1):38-41.

14. World Health Organization. Oral Health Surveys: basic methods. $4^{\text {th }}$ ed. Geneve: WHO; 1997.

15. Associação Brasileira de Empresas de Pesquisa (ABEP). Critério de Classificação Econômica Brasil. [acesso 12 jan 2003]. Disponível em: http://www.abep.org/codigosguias/ABEP_CCEB.pdf.

16. Simões CCS. Mortalidade infantil na década de 90 e alguns condicionantes sócio-econômicos. In: Simões CCS. Perfis de saúde e de mortalidade no Brasil: uma análise de seus condicionantes em grupos populacionais específicos. Brasília: Organização Panamericana da Saúde; 2002. p. 51-86.

17. Kawabata K, Kawamura M, Sasahara H, Morishita M, Bachchu MAH, Iwamoto Y. Development of an oral health indicator in infants. Community Dent Health. 1997;14(2):79-83.

18. Mayall B. Keeping children healthy: the role of mothers and professionals. London: Allen \& Unwin; 1986.

19. Watt $\mathrm{R}$, Sheiham A. Inequalities in oral health: a review of the evidence and recommendations for action. Br Dent J. 1999;187(1):6-12. 
Determinant factors of toothache in 8-and 9-year-old schoolchildren, Belo Horizonte, MG, Brazil

20. Woodward GL, Leake JL, Main PA. Oral health and family characteristics of children attending private or public dental clinics. Community Dent Oral Epidemiol. 1996;24(4):253-9.
21. Macfarlane TV, Blinkhorn AS, Davies RM, Kincey J, Worthington HV. Oro-facial pain in the community: prevalence and associated impact. Community Dent Oral Epidemiol. 2002;30(1):52-60. 